\title{
Design of an intelligent MPPT based on ANN using an experimental photovoltaic system data
}

\author{
Sadeq D. Al-Majidi ${ }^{1,2}$ \\ Sadeq.Al-Majidi@brunel.ac.uk
}

\author{
Maysam F. Abbod ${ }^{1}$ \\ Maysam.Abbod@brunel.ac.uk
}

\author{
Hamed S. Al-Raweshidy ${ }^{1}$ \\ Hamed.Al-Raweshidy@brunel.ac.uk
}

\author{
${ }^{1}$ Department of Electronic and Computer Engineering, College of Engineering, Design and Physical Sciences, Brunel University \\ London, Uxbridge UB8 3PH, United Kingdom \\ 2 Department of Electrical Engineering, College of Engineering, University of Misan, Amarah 62001, Iraq
}

\begin{abstract}
Maximum power point tracking (MPPT) methods are an essential part in photovoltaic (PV) system design for increasing the output power of a PV array. Whilst several methods have been introduced, the artificial neural network (ANN) is one of the most powerful method for MPPTs due to its less oscillation and fast response. However, accurate training data is a big challenge to design an optimized ANN-MPPT technique. In this paper, an ANN-MPPT technique based on a large experimental training data is proposed to avoid the system from having a high training error. Those data are collected during one year from experimental tests of a grid-connected PV system installed at Brunel University, London, United Kingdom. The irradiance and temperature of weather conditions are selected as the input, and the maximum power from the PV system as the output of the ANN model. To assess the performance, the Perturb and Observe (P\&O) and the proposed ANN-MPPT methods are simulated using a MATLAB/Simulink model for a PV system. The results show that the proposed ANN method accurately tracks the optimal maximum power point and avoids the phenomenon of drift problem, whilst achieving a higher output power when compared with P\&O-MPPT method.
\end{abstract}

Keywords- Artificial Neural Network (ANN), Maximum power point tracking (MPPT), photovoltaic (PV) and Perturb and Observe (P\&O).

\section{INTRODUCTION}

Nowadays, the global demand for energy is growing dramatically due to population growth. Moreover, global warming phenomenon has been intensified because of the $\mathrm{CO}_{2}$ emissions from traditional fossil fuels. To address those issues, many scholars have turned to renewable energies to face the issue of lack of energy in coming years and to minimize the side effects of burning traditional fossil fuels. The major renewable energy resources are a photovoltaic (PV) systems, wind turbines, hydropower, and geothermal power. However, the PV system is one of the most engaging renewable energy resources, owing to its provision of sustainable, clean and safe energy [1]. Regarding to the International Energy Agency (IEA), global energy generation from PV resources will reach
$16 \%$ of global production of electricity by 2050s [2]. Unlike, the major problem is a low efficiency when installing this resource, because the generated power from a PV system depends upon the irradiance level and temperature operation, which can result in losses of energy of up to 25\% [3]. The most effective method to improve the efficiency of a PV system is to employ a maximum power point tracking MPPT with a PV array, as shown in Fig 1, thereby achieving maximum power generation under varying weather conditions. Basically, the MPPT technique is a controller, which generates an appropriate duty ratio (D) to a DC-DC convertor for the output (current and voltage) and/or input (irradiance and temperature) of the PV array to achieve continuous maximum power production. In general, cost, efficiency, lost energy, and type of implementation are the major key issues when aiming to propose the MPPT method for PV systems [4]. Taking these into account, many types of MPPT methods have been proposed, which can be divided into two types: classical techniques, such as Perturbation and Observation (P\&O) [5], and Incremental Conductance (IC) [6]; and Artificial Intelligent (AI) techniques, for instance, Fuzzy Logic Controller (FLC) [7], Artificial Neural Network (ANN) [8] Adaptive Neural-fuzzy Interference System (ANFIS) [9].

The P\&O-MPPT is a widely technique used for PV-MPPT due to its simple implementation and low cost [10]. However, this faces several problems, such as lower response time, high fluctuation, and drift problem phenomenon [11]. Hence, several modifications have been proposed to address those issues, such as in Refs. [2, 12-14], but they are considered as non-optimal solutions. Consequently, the AI techniques based on MPPT have been developed to solve these limitations. Furthermore, these methods do not need accurate parameters and complex mathematics when managing the system. The FLC-MPPT is one of the most powerful intelligent controllers for a PV system due to its high response and lesser oscillation, when compared with traditional MPPT methods. However, the major disadvantages are the phenomenon of drift problem associated with a change in the irradiance level and temperature operation [7]. This is because it heavily depends 
on the good knowledge of PV systems, resulting in inaccurate membership functions. To address this issue, many modifications have been proposed, for example, an adaptive and optimized membership function of the traditional FLCMPPT, as evidence in [7, 15-17]. However, the implementation is become over complex. The ANN technique is another powerful intelligent method for a nonlinear system, such as a PV module. The major benefits of using ANN with PV-MPPT systems are that there is no requirement for knowledge on the internal system parameters, less computational time and it provides a compact solution for multivariable problems [18]. Hence, the ANN- MPPT method has a faster response time and less oscillation around the maximum power point. However, getting accurate training dataset is a big challenge to design an optimized ANN-MPPT technique [19]. Therefore, several types of ANN-MPPT methods have been proposed using various types of training data, such as in Refs. [20-22].

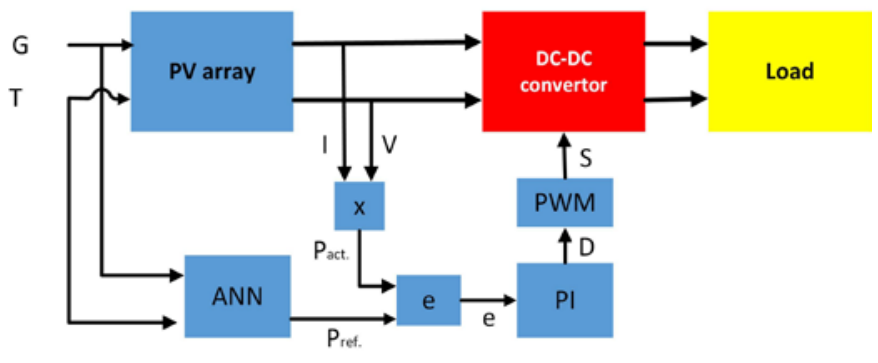

Fig. 1 a scheme diagram of PV system based MPPT.

In this paper, ANN technique is used to determine the maximum power point of a PV array based on large real training dataset. Those for the ANN model are collected from experimental tests of a PV array installed at Brunel University, London, United Kingdom. The irradiance level and temperature operation are selected as the input, and the reference power (Pref.) of the PV array at the maximum power point as the output. In the same environmental conditions, actual PV power (Pact.) is measured using a sensed the voltage and current of a PV Simulink operation. These two power sources are compared, and the error (e) is given to a proportional integral (PI) controller to generate the duty ratio of a DC-DC boost convertor, and this duty ratio is converted to the signal (S) by a Pulse-width modulation (PWM) to adjust the operating the maximum power point of the PV array, as shown in Fig. 1. The results demonstrate that the proposed ANN method has the lower tracking time, less oscillation around the maximum power point, and the higher output power. Moreover, it is the most accurate for tracking the maximum power point and avoiding the phenomenon of drift problem. The rest of this paper is organized as follows. Section II covers the PV system, while Section III and section IV introduce the MPPT using the P\&O and ANN algorithms. In section $\mathrm{V}$, the results are provided and discussed. Finally, section VI presents the conclusion.

\section{PV SYSTEM}

The studied PV system comprises a $925 \mathrm{~W}, 5$ modules (Sharp NU-S5E3E 185) of PV array installed at the Brunel University London, United Kingdom, as shown in Fig. 2. A dynamic simulation model of the PV system is designed under MATLAB/ Simulink to analyse and discus the performances of the proposed ANN-MPPT method.

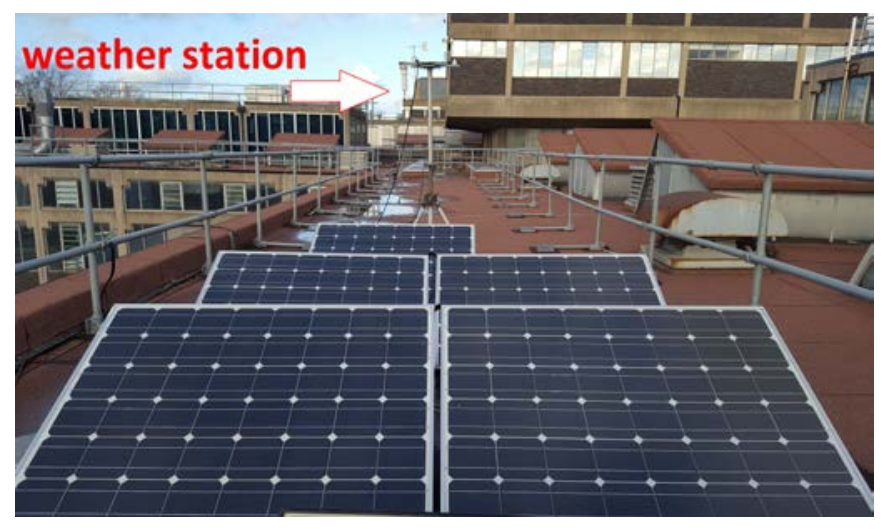

Fig. 2. The studied PV array installed at Brunel University London

A PV cell is a crucial part in a PV system that converts the light into electrical energy. In ideal PV cell system, parallel and series resistances are not included, but in practical case, they are introduced due to a leakage current and ohmic resistances as shown in Fig. 3. The main contributor of the shunt resistance $R_{s h}$ is that a p-n junction of Photovoltaic diode is non-optimal, while the series resistance $R s$ is the bulk resistance of semiconductor material and interconnections. Kirchhoff's law, as given in equation (1) can find the output current from the solar PV cell:

$$
I_{P V}=I_{L}-I_{d}-I_{s h}
$$

where $I_{L}$ is the light generated current is given as equation (2):

$$
I_{L}=G\left\{I_{S C}\left[1+a\left(T-T_{S T C}\right)\right]\right\}
$$

where, $G$ is the solar irradiance level, $T$ is the ambiance temperature operation, $I_{S C}$ is the PV short circuit current, $k a$ is the temperature coefficient, $T_{S T C}$ is the ambiance temperature for the PV cell under standard test conditions (STC), and $I_{d}$ is the diode current which is given as equation (3):

$$
I_{d}=I_{0}\left\{\exp \left(\frac{q V_{d}}{n k T}\right)-1\right\}
$$

where $I_{0}$ is the reverse saturation current of the PV diode, and $V_{d}$ is the Voltage across the diode, $k$ is the Boltzmann's constant $\left(1.38 \times 10^{-23} \mathrm{~J} / \mathrm{K}\right), q$ is the electric charge $\left(1.69 \times 10^{-19}\right.$ 
$\mathrm{C}$ ), and $\mathrm{n}$ is the diode factor. The general equation that describes the P-V characteristic curve of the PV cell is given in equation (4):

$$
I_{P V}=I_{L}-I_{0}\left[\exp \left(\frac{q\left(V_{P V}+I R_{S}\right)}{n k T}\right)-1\right]-\left[\frac{V_{P V}+I R_{S}}{R_{S h}}\right]
$$

where $I_{P V}$ is the PV output current, and $V_{P V}$ is the PV output voltage. PV cells are connected in series and parallel to obtain desired voltage and current respectively for the PV panel, and then this PV panels are connected in series and/or parallel to give different configurations of photovoltaic array.

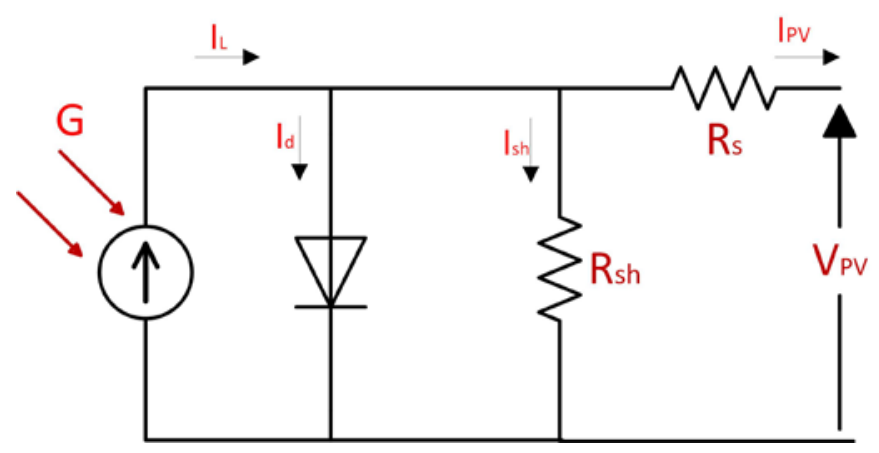

Fig. 3. Equivalent circuit of a PV cell.

As shown in Fig. 4, there are unique points on the P-V curve of the PV array, which are known as the maximum power point (MPP) and the location of those points depends on irradiance and temperature of weather conditions: the maximum power increases as irradiance level increases, conversely a PV generator better for low operating temperature than raised one. On top of that, the power generator of the PV array depends upon the impedance of the load. When the PV array is connected to the load, it drops to a new operating point. To address those issues, power conversion system with MPPT technique is employed between PV array and the load or invertor, as shown in Fig.1. In general, there are several types of DC-DC converters, the boost DC-DC converter is widely used for PV systems because of its easily adapted MPPT controller and high efficiency. The DC-DC boost converter is used to regulate and provide the output voltage that its level is more than the input voltage. The voltage gain of DC-DC boost converter is given as equation (5):

$$
G_{n}=\frac{V_{o}}{V_{i}}=\frac{1}{(1-D)}
$$

where $V_{o}$ is the output voltage, $V_{i}$ is the input voltage, and $D$ is the duty ratio of MPPT controller, which is converted to a signal by the PWM to adjust the operating the maximum power point of the PV array.

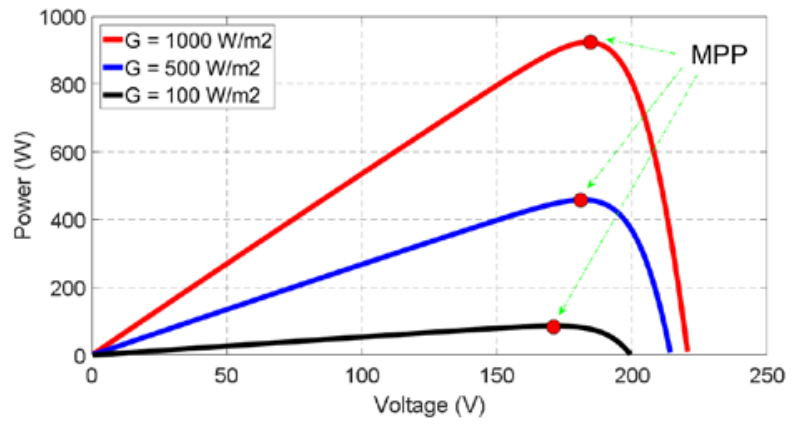

(a)

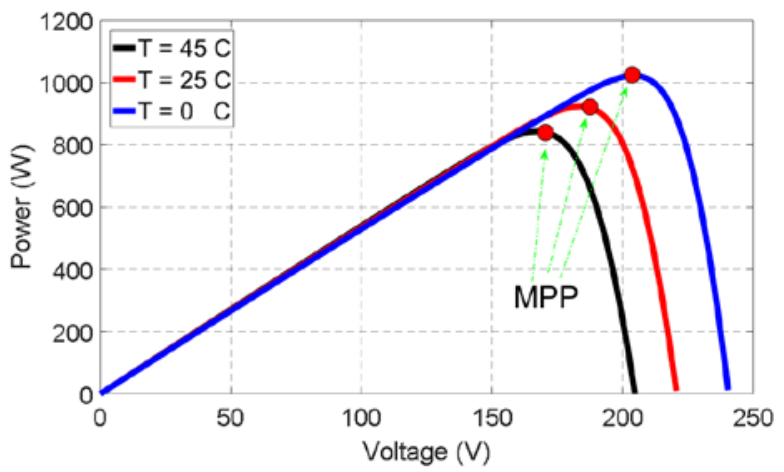

(b)

Fig. 4 P-V curve of a PV array under; (a) varying values of irradiance at constant temperature of $25 \mathrm{C}^{\circ}$, (b) varying values of temperature at constant irradiance of $1000 \mathrm{~W} / \mathrm{m}^{2}$,

\section{P\&O-MPPT ALGORITHM}

The Perturb and Observe (P\&O) method is widely used for PV-MPPT technique due to its simple implementation and low cost. The principle work of this method, as shown in Fig. (5), is that it calculating the PV power by using the sensed values of the voltage and current, and then, it compares with the previous PV power and voltage, with the direction of the algorithm being adjusted accordingly and a reference voltage of the boost converter being adjusted as equation (6):

$$
\operatorname{Vref}_{\cdot_{k+1}}=\operatorname{Vref}_{\cdot_{k}} \pm \Delta V
$$

where Vref. $\cdot_{k+1}$ and Vref $\cdot{ }_{k}$, are the next and previous perturbation of the reference voltage respectively, and $\Delta \mathrm{V}$ is the incremental increase in the reference voltage. If the tendency of change in the PV power and PV voltage increase regarding to an increase in the reference voltage, the control system moves in the same direction; otherwise the operating point moves in the opposite direction. The processing work of the algorithm is continued until it reaches to the optimized MPP point and then it oscillates around it. In general, there are three main problem facing its operation: a low response time, high oscillation around the MPP point and a phenomenon of drift problem associated with the input irradiance changing 
rapidly. In other hand, this problem is happened when the input solar irradiance increases only [7]. To address these issues, several proposed P\&O-MPPT methods have been developed such as a variable step size and modified P\&O algorithm. However, they are considered non-optimized solutions to address all of these issues. Consequently, artificial intelligence techniques based on MPPT method have been developed to overcome the limitations of the traditional P\&OMPPT method.

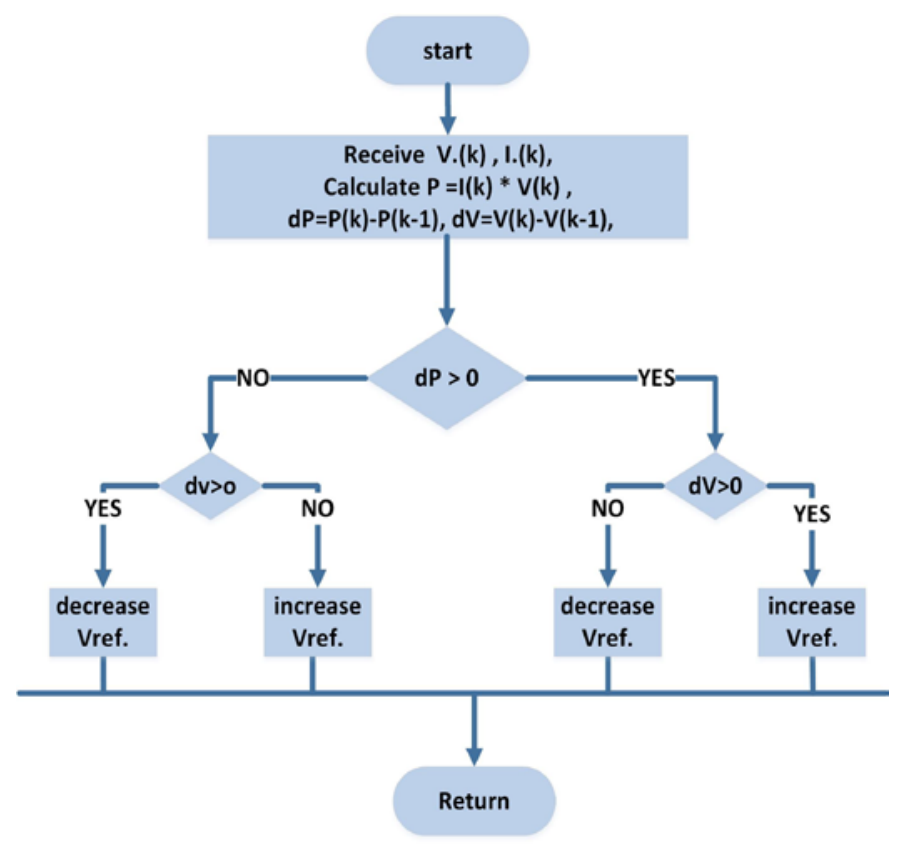

Fig. 5. Flowchart of a $\mathrm{P} \& \mathrm{O}$ algorithm

\section{ANN-MPPT METHOD}

ANN based on MPPT controller has been widely used for PV systems due to its ability to track the MPP under different weather conditions. The developed architecture of ANN model consists of three layers; input, hidden and output as shown in fig.6. In this work, the input layer consists the irradiance and temperature of weather conditions, while the output layer is the reference power of the installed PV array at the MPP. In the same environmental conditions, PV power of Simulink operation is measured using a sensed voltage and the current. These two powers are compared, the error (e) is given to PI controller to generate the duty ratio of a DC-DC boost convertor, and this duty ratio is converted to the signal by PWM to adjust the operating MPP of the PV array. The ranges of the irradiance and temperature are collected according to the latitude and longitude of Uxbridge, London, United Kingdom, which are 51.531 and -0.474 , respectively. In the grid-connected Brunel laboratory, the PV system and weather station are connected to a Sunny Boy data logger. Both the weather station and PV system are controlled and monitored through a supervisory control and data acquisition (SCADA) cum data logger connected to a PC computer terminal and linked to the internet though Brunel university's local area network (LAN). The 48,000 datasets were collected daily at each 5 minutes' intervals for one year to get the accurate training data. This data has been divided into sub-data; 70\%, $15 \%$ and $15 \%$ to train, test and validate the ANN network respectively. To get the optimized activation function in hidden layer, five neurons is used which achieve less tolerance of Mean Square Error (MSE) about 0.0075, as shown in Fig. 7. In general, the MPPT technique based on ANN is designed to solve the limitations of a classical methods. Additionally, the tracking power of ANN-MPPT has a faster response and less oscillation under varying weather conditions. However, accurate training data is a big challenge when designing an optimal ANN-MPPT method.

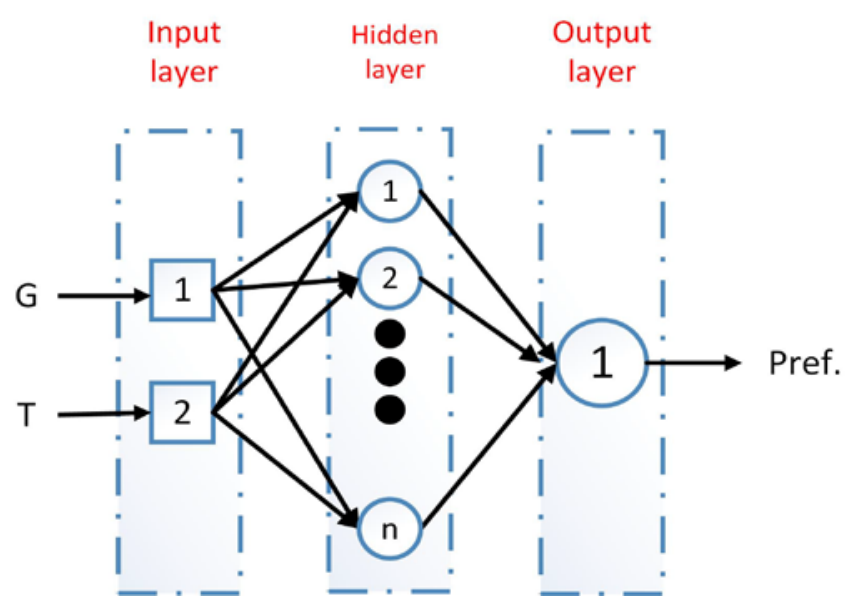

Fig. 6. A block diagram of the ANN mode

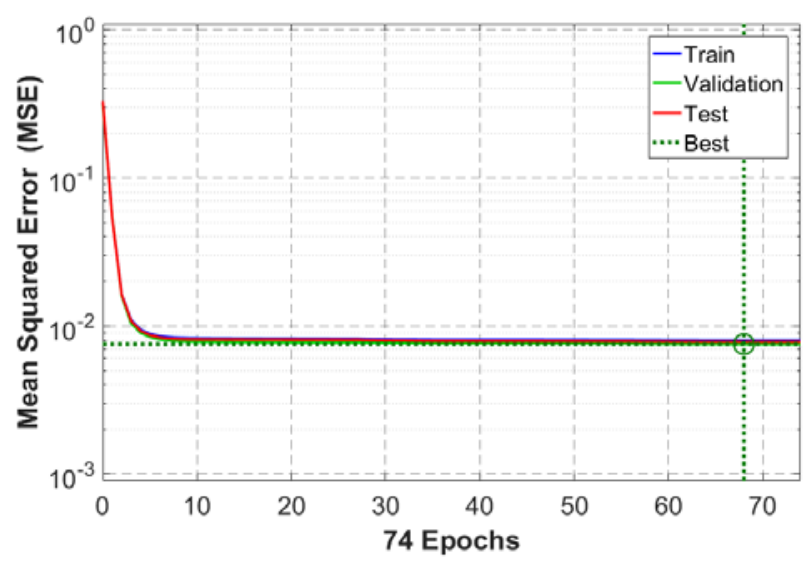

Fig. 7. Mean squared error versus epochs for the proposed ANN model 
Table 1. A comparison of the properties of the ANN and P\&O-MPPTs

\begin{tabular}{|l|l|l|l|l|}
\hline MPPT & $\begin{array}{l}\text { Tracking } \\
\text { time (s) }\end{array}$ & Oscillation & $\begin{array}{l}\text { Drift } \\
\text { problem }\end{array}$ & $\begin{array}{l}\text { Output } \\
\text { power (W) }\end{array}$ \\
\hline ANN-MPPT & 0.06 & low & avoidance & 924.2 \\
\hline P\&O-MPPT & 0.12 & High & suffering & 922.5 \\
\hline
\end{tabular}

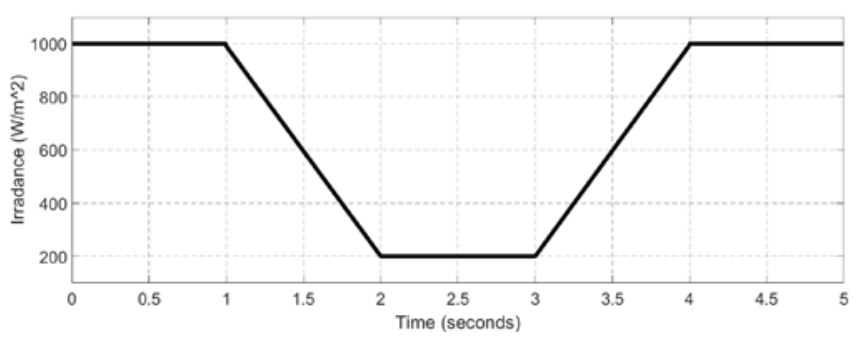

Fig.8. the input of solar irradiance level.

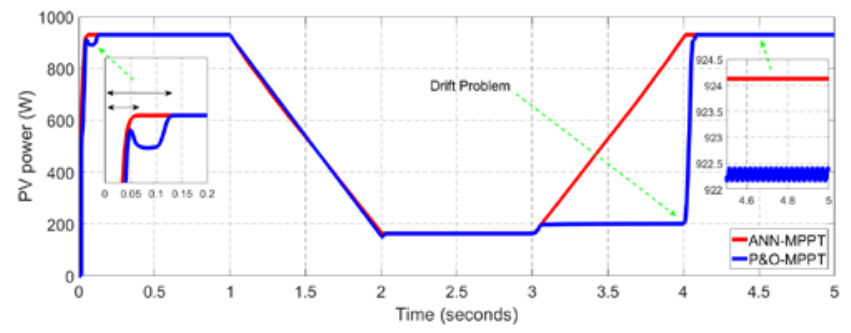

(a)

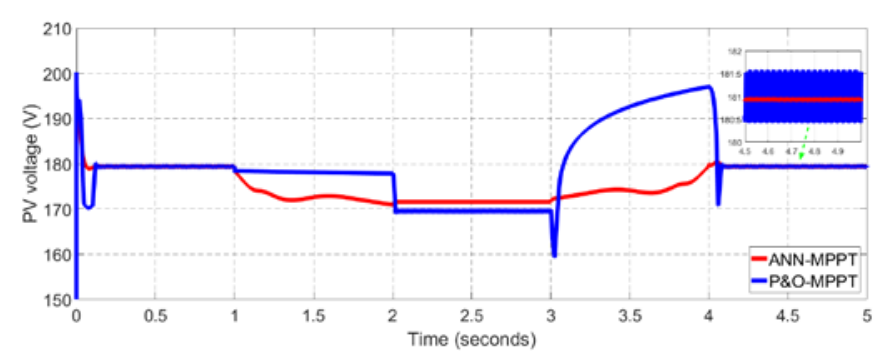

(b)

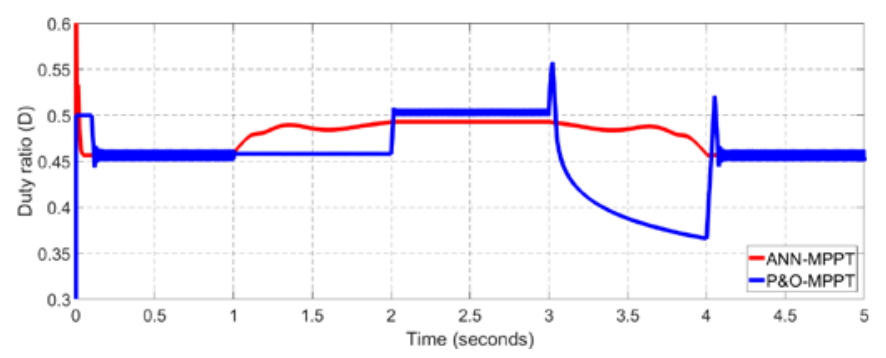

(c)

Fig. 9. PV array output for a conventional P\&O-MPPT VS the proposed ANN-MPPT under fast change in solar irradiance; (a) power, (b) voltage, and (c) duty ratio.

\section{Simulation Results}

To evaluate the performance, the $\mathrm{P} \& \mathrm{O}$ and ANN-MPPT methods are simulated using a MATLAB/Simulink model for a PV system. This PV system consists of a PV array, DC-DC boost converter, MPPT micro-controller and a load. The installed PV array consists of five PV modules connected in series. The main parameters of the PV module under standard test conditions are $185 \mathrm{~W}$ maximum power, $36.21 \mathrm{~V}$ optimized voltage, 5.11 A optimized current, $44.9 \mathrm{~V}$ open circuit voltage and 5.75 A short circuit current. As shown in Fig. 8, the input irradiance level of the simulation scenario was faster decreased rapidly from 1000 to $200 \mathrm{~W} / \mathrm{m}^{2}$ at 1 to $2 \mathrm{~s}$, and then increased rapidly from 200 to $1000 \mathrm{~W} / \mathrm{m}^{2}$ at 3 to $4 \mathrm{~s}$, and the temperature operation was kept at $25{ }^{\circ} \mathrm{C}$. As shown in in the zoom in of Fig. 9(a), the tracking time of the ANN-MPPT method is the faster when compared to P\&O-MPPT method, being about $0.07 \mathrm{~s}, 0.12 \mathrm{~s}$, respectively. In addition, the power tracker of the ANN-MPPT method turned out to be accurate in finding the right direction, whilst that of the P\&O-MPPT method was lost it when the input irradiance level increased rapidly.

As a result, the later takes a longer time than MPPT based on ANN to solve the drift problem, as shown in Fig. 9(a). Moreover, it has the lesser smooth oscillation around the optimal MPP for steady-state conditions, thus resulting in less computation time, as shown in the zoom in of Figs. 9(b). Alternatively, the fluctuation problem is the higher in the P\&O-MPPT method because of the continuous perturbation of the $\mathrm{P} \& \mathrm{O}$ tracker for reaching the optimal MPP. Consequently, the lost power in ANN-MPPT is lesser than for P\&O-MPPT technique. Hence, the output power of ANN-MPPT and P\&OMPPT methods, after they have reach the optimal MPP, are about $924.2 \mathrm{~W}$ and $922.5 \mathrm{~W}$, respectively, as shown in the zoom in of Fig. 9(a). To assess ANN-MPPT method further, table 1 compares its properties with P\&O-MPPT method. As can be seen, ANN-MPPT has the faster tracking time, the lesser oscillation around the MPP and the higher output power generation. Moreover, it is the most accurate in tracking the optimized MPP and avoiding the drift problem.

\section{CONCLUSION}

An intelligent maximum power point tracking method based on an artificial neural network using an experimental data of a PV system has been proposed. The large training dataset is collected during one year from the experimental testing of the PV system installed at Brunel University, London, United Kingdom. The irradiance and temperature of weather conditions are selected as the inputs, whilst the maximum power from the PV system as the output of ANN model. Under the same environmental conditions, actual PV power is measured using a sensed voltage and the current of a PV Simulink operation. These two power outputs are compared, and the error is given to a proportional integral controller to 
generate the signal of a DC-DC convertor by the PWM generator, to adjust the operating MPP of the PV array. To sum up, the mythology of collected data and the tuning of proposed ANN model are explained. The P\&O and the proposed ANN-MPPT methods are simulated using a MATLAB/Simulink. The results demonstrate that the proposed ANN method exhibits higher output power, and no divergence from the optimal maximum power point during varying weather conditions.

\section{ACKNOWLEDGMENT}

The corresponding author is grateful to University of Misan and the Iraqi Ministry of Higher Education and Scientific Research for financially supporting the current research.

\section{REFERENCES}

[1] V. Verma, A. Kane, and B. Singh, "Complementary performance enhancement of PV energy system through thermoelectric generation,” Renew. Sustain. Energy Rev., vol. 58, pp. 1017-1026, 2016.

[2] S. D. Al-Majidi, M. F. Abbod, and H. S. Al-Raweshidy. "A Modified P\&O-MPPT based on Pythagorean Theorem and CVMPPT for PV Systems” 2018 53rd International Universities Power Engineering Conference (UPEC), 2018.

[3] E. Román, R. Alonso, P. Ibañez, S. Elorduizapatarietxe, and D. Goitia, "Intelligent PV Module for Grid-Connected PV Systems," IEEE Transactions on Industrial Electronics, vol. 53, no. 4, pp. 1066-1073, 2006.

[4] Z. Salam, J. Ahmed, and B. S. Merugu, "The application of soft computing methods for MPPT of PV system: A technological and status review,” Appl. Energy, vol. 107, pp. 135-148, 2013.

[5] N. S. D. Souza, L. A. C. Lopes, and X. Liu, "Comparative study of variable size perturbation and observation maximum power point trackers for PV systems," Electric Power System Research, vol. 80, pp. 296-305, 2010.

[6] M. A. Elgendy, B. Zahawi, S. Member, and D. J. Atkinson, "Assessment of the Incremental Conductance Maximum Power Point Tracking Algorithm," IEEE Transactions on Sustainable Energy, vol. 4, no. 1, pp. 108-117, 2013.

[7] S. D. Al-Majidi, M. F. Abbod, and H. S. Al-Raweshidy, "A novel maximum power point tracking technique based on fuzzy logic for photovoltaic systems," International Journal of Hydrogen Energy, 2018.

[8] M. Seyedmahmoudian et al., "State of the art artificial intelligencebased MPPT techniques for mitigating partial shading effects on PV systems - A review,” Renew. Sustain. Energy Rev., vol. 64, pp. 435-455, 2016.

[9] M. A. Enany, M. A. Farahat, and A. Nasr, "Modeling and evaluation of main maximum power point tracking algorithms for photovoltaics systems,” Renew. Sustain. Energy Rev., vol. 58, pp. 1578-1586, 2016.

[10] F. Paz and M. Ordonez, "Zero oscillation and irradiance slope tracking for photovoltaic MPPT,” IEEE Trans. Ind. Electron., vol. 61, no. 11, pp. 6138-6147, 2014.

[11] V. Kamala Devi, K. Premkumar, A. Bisharathu Beevi, and S. Ramaiyer, "A modified Perturb \& Observe MPPT technique to tackle steady state and rapidly varying atmospheric conditions," Sol. Energy, vol. 157, no. August, pp. 419-426, 2017.

[12] . K. Kollimalla, S. Member, M. K. Mishra, and S. Member, "A Novel Adaptive P \& O MPPT Algorithm Considering Sudden Changes in the Irradiance," IEEE Transactions on Energy Convertions, vol. 29, no. 3, pp. 602-610, 2014.

[13] R. Alik and A. Jusoh, "An enhanced P\&O checking algorithm
MPPT for high tracking efficiency of partially shaded PV module," Sol. Energy, vol. 163, no. November 2017, pp. 570-580, 2018.

[14] M. Killi and S. Samanta, "Modified Perturb and Observe MPPT Algorithm for Drift Avoidance in Photovoltaic Systems," IEEE Transactions on Industrial Electronics, vol. 62, no. 9, pp. 55495559, 2015.

[15] T. H. Kwan and X. Wu, "Maximum power point tracking using a variable antecedent fuzzy logic controller," Sol. Energy, vol. 137, pp. 189-200, 2016.

[16] O. Guenounou, B. Dahhou, and F. Chabour, "Adaptive fuzzy controller based MPPT for photovoltaic systems,” Energy Convers. Manag., vol. 78, pp. 843-850, 2014.

[17] Y. Soufi, M. Bechouat, and S. Kahla, "ScienceDirect Fuzzy-PSO controller design for maximum power point tracking in photovoltaic system,” Int. J. Hydrogen Energy, vol. 42, no. 13, pp. 8680-8688, 2016.

[18] C. Ben Salah and M. Ouali, "Comparison of fuzzy logic and neural network in maximum power point tracker for PV systems," Electr. Power Syst. Res., vol. 81, no. 1, pp. 43-50, 2011.

[19] T. Hiyama, S. M. Ieee, and K. Kitabayashi, "Neural Network Based Estimation of Maximum Power Generation from PV Module Using Environmental Information" IEEE Transactions on Energy Conversion," vol. 12, no. 3, 1997.

[20] F. Almonacid, E. F. Fernández, and P. Rodrigo, "Estimating the maximum power of a High Concentrator Photovoltaic ( HCPV ) module using an Arti fi cial Neural Network,” Energy, vol. 53, pp. 165-172, 2013.

[21] A. Chaouachi, R. M. Kamel, and K. Nagasaka, "A novel multimodel neuro-fuzzy-based MPPT for three-phase grid-connected photovoltaic system,” Sol. Energy, vol. 84, no. 12, pp. 2219-2229, 2010.

[22] A. Gupta, P. Kumar, R. K. Pachauri, and Y. K. Chauhan, "Performance Analysis of Neural Network and Fuzzy Logic Based MPPT Techniques for Solar PV Systems,” 2014 6th IEEE Power India Int. Conf., pp. 1-6, 2014. 